\title{
A VERY HUMAN SURVEY: THE CROSS-CULTURAL INQUIRIES OF R. H. MATHEWS
}

\author{
MARTIN THOMAS
}

Public History ReVIeW, VOL 12, 2006, PP12-26

$\mathrm{L}$ et us enter the archive with words from Mathews himself. ${ }^{1} \mathrm{He}$ is introducing what would be his longest paper, 183 pages in length. Dated 1904, it was called 'Ethnological Notes on the Aboriginal Tribes of New South Wales and Victoria'. This plain, descriptive title is characteristic of a man who was cautious of pomposity or embellishment. He presents himself in the following way:

Throughout a comparatively long life I have had special opportunities of studying the habits of these people. I was born in the Australian bush and black children were among my earliest playmates. In my youth I was engaged in station pursuits in the back blocks of New South Wales and in the new country of Queensland, when the blacks were in their pristine condition. In later years I was employed by the Government as a surveyor on the Barwon, Namoi, Castlereagh, and other distant inland rivers, where I was continually in contact with the sable sons and daughters of the soil.

Fortunately, also, I always had a keen proclivity for collecting all the information available in regard to their numerous highly interesting customs... Owing to my familiarity with the ways of blackfellows, I always received the complete confidence of the chief men, and thus gained admission to their secret meetings. Moreover, my training as a draftsman enabled me to copy every description of aboriginal drawing with great facility... And the knowledge of astronomy which my profession demanded made it easy for me to identify with precision all the different stars and stellar groups which figure so prominently in the aboriginal folklore...

I have adopted none of the opinions nor followed any of the methods of other Australian authors, but have struck out on my own lines, recording all the new and interesting facts within my 
reach. Possibly further researches may modify some of my conclusions, but this is the inevitable lot of all scientific pioneers.

I write not in the expectation of exhausting the subject of the languages, ceremonies and customs of the Australian aborigines, but in the fervent hope of exciting the interest and encouraging the investigation of younger students; and trust that some foundations have been laid by me for others to build upon, or to correct if necessary. ${ }^{2}$

Such are the words of Robert Hamilton Mathews (1841-1918), surveyor and anthropologist. His first anthropological publication was 'Rock Paintings by the Aborigines in Caves on Bulgar Creek, near Singleton', published by the Royal Society of New South Wales in 1893. His last appeared in 1918, the year he died. His papers number about 170 . With their descriptive titles, often painfully similar, the Mathews canon is a bibliographer's nightmare. Even his allies knew this to be the case. The sociologist, Arnold van Gennep, a member of the Durkheim set, wrote from Paris in 1907: 'You are overlooked because your papers are so scattered.' Mathews was advised to immediately organise their 'publication in 2 or 3 volumes. ${ }^{3}$ Van Gennep wrote again in 1909: 'Really, it is a pity that you are not taking all your publications in one systematical work... [It] is impossible to get at your definitive ideas about this or that tribe and about the relations of the whole of your inquiries, etc. ${ }^{4}$

Such urgings notwithstanding, the magnum opus never appeared. Instead, Mathews wrote a tremendous number of journal articles which were published in Britain, the United States, Australia, France, Germany and Austria. Most Australians have little sense of the global appetite for data on Aborigines - the fascination in 'savagery' - during those turn-of-the-century years. Mathews and a few other researchers, with whom he mainly argued, fed the market and watched, sometimes with dis-ease, while the armchair ethnologists as they called them, published the big books - some remembered, more forgotten. Editors accepted Mathews' work even when they bemoaned its want of theory, its failure to speculate, in that evolutionist age, on the origins of 'man'. But Mathews kept publishing his often short papers, accounts from the field, spreading himself perhaps too thin.

What drove him to abandon the life of a comfortable self-made man, a coroner and magistrate, in his quest for data about Aborigines? I searched his publications and then the fourteen archive boxes in the Manuscripts Collection of the National Library of Australia (NLA). There are diaries, drafts, notes, letters. None of it is entirely satisfactory. The snatches of memoir like the one quoted above are fragmentary; nothing extended. The diaries are sketchy with their one line entries. No inner dialogue, no motivations or revelations: bones not flesh. And there are letters - hundreds of them - from all his informants across the country. But these are letters in, not out. They lack the voice of the collector. This archive is like a carapace. I sense his general shape but not his substance. The 
occupant has long since left.

Mr Mathews, where are you? Impressions, impressions - a friend's account. The informant: W. J. Enright, lawyer and amateur ethnologist. He wrote a paper on the initiation ceremonies of the Aboriginal people of Port Stephens, NSW, which was published in 1899:

I mentioned the difficulties I encountered in obtaining particulars of their secret ceremonies to my friend Mr. R. H. Mathews, from whom I have always received encouragement and assistance... and on his next visit to Maitland he drove out with me to the native camp... He was personally known to some of the men present there, and was at once received by them as one of the initiated. I remained in the camp 'with the women and children,' as they jocularly expressed it, while Mr. Mathews took all the initiated men to a secluded place... ${ }^{5}$

There are the words of a friend and confidant, with their fascinating revelation of how Mathews could be accepted as part of an Aboriginal inner circle. But they were not all friends. Very early in his publishing career, Mathews fell out with W. Baldwin Spencer, co-author - with F. J. Gillen - of The Native Tribes of Central Australia (1899), arguably the most significant anthropological monograph of its era. Writing to his friend Lorimer Fison from the Northern Territory in 1901, Spencer complained:

That man Mathews (R. H. not the Rev) has been plying everyone all along the line with questions. Fortunately most of the people have taken no notice of him but he has got some information of a certain kind from one or two people some of which we know to be erroneous. He is a nuisance and will do more harm than good! ${ }^{6}$

But Fison, also a pioneer anthropologist, was already implicated in the feud with Mathews. Spencer would go further, communicating his opinion to some of the biggest names on the anthropological scene. One of the fascinations of this research is charting the ways in which extremely localised descriptions from the Australian back-blocks were feeding into international scientific debate. When in 1903 Spencer read to his horror that Andrew Lang, perhaps the most prolific man of letters in Britain, had appreciatively described Mathews as the most lucid and 'well informed writer on the various divisions which regulate the marriages of the Australian tribes', ${ }^{7}$ he vented his anger to no one less than J. G. (later Sir James) Frazer, author of that strange multi-volume work (to some a masterpiece), The Golden Bough. Spencer unjustly accused Mathews of plagiarising Howitt. 'The trouble,' wrote Spencer, 'is that Mr M. pours out so many papers that writers at home [meaning Britain] who cannot know anything of the way in which he gets his information are apt to think that he is reliable. ${ }^{8}$ Later character assassination 
must have followed, for a letter survives from 1908 in which Frazer says to Spencer:

As for that fellow R. H. Matthews [sic], of course I shall not even mention him or any of his multitudinous writings. He wrote to me twice in a tone which showed the character of the man. I did not answer his letters and shall hold no communication with him. ${ }^{9}$

Here are traces of feuding that was catastrophic for Mathews' reputation. He had been peddling a book proposal to Macmillan in London. This was the publisher of Frazer and Spencer - and quite possibly it went to Frazer for review. These were early days in the discipline's history. There was no university anthropology in Australia until 1925. Even Spencer, a biologist at Melbourne University, was doing it on the side. Mathews had no institutional affiliation beyond membership of some scientific societies, no government support as did Daisy Bates (with whom he corresponded) and few allies within the academies. Yet more than this, the fighting that went on - and Mathews at times was to give as good as he got is deeply reflective of the era with its unqueried assumption that Aboriginal culture, or the 'customs' and 'habits' as they tended to call it, was, like the land Mathews measured for a living, territory that could be simply claimed and divided.

It becomes a detective game, trying to make sense of it, thinking about what drove him, about how far he became immersed in the 'habits and customs' and how his curiosity resonates with a broader desire to unravel the deep human mysteries that were presented as the conquest of this continent took hold. The desire to engage with the secrecy of ritual is an old one. I leaf through the beautiful album of watercolours by convict artist Joseph Lycett, sharing his fascination for the painted figures who corroboree the night away. I turn through the sumptuous folio prepared by Louis de Freycinet, Voyage auteur du monde (1839), with its glorious Aboriginal portraits drafted around Sydney. The marks of scarification are visible on the subjects' bodies: outer signs of things hidden ceremony, secrecy, pain. They seem to delineate a threshold that one can never cross as an outsider. Browsing through books, donning the white conservators gloves, the connections become ever more labyrinthine, the conjunctions stranger. A Mathews bookplate is pasted on the inside cover of Voyage auteur du monde. The owner was not R. H. Mathews. He would never have owned an antiquarian treasure like this. No, it was part of a collection of 5000 books donated to the Commonwealth by Robert's son, Gregory M. Mathews, who married into the pastoral money of the Hunter Valley's White family. An ornithologist and bibliophile, he devoted time and fortune to the writing and production of the 7000 page multi-volume Birds of Australia, a modern book to rival Gould. At least someone got to write their magnum opus.

Negotiating this legacy, as elaborate and nuanced as the landscapes Mathews mapped and measured for a living, presents real challenges. What story could one weave about something like this, a white man's desire, as our present- 
day idiom puts it, to gather and publish all possible data about the 'other'? Yet here I think the problem and perhaps the grain of a solution might just lie. Could it be that all the talk of 'otherness' that haunts post-colonial theory is really about the theorist's attempt to contain rather than overcome difference, keep it at bay, have it remain the inert anthropological object about which one can speculate forever? For when I look through these papers which are not without prejudice (forget political correctness) and not without aspersions about the inveterate laziness of the blacks, I see not the barrier of 'otherness' but long sessions of patient discussion and note-taking, the hours that R. H. Mathews spent at the blacks camp at La Perouse, for instance, with old Queen Timbery, filling notebooks with language and beliefs of the Dharawal. I think of his transition, going from a topographical to a human survey - the two are not exclusive where Aborigines are concerned - which would turn the railway maps he used, collected, and filled with ethnological data, into something new and yet very old an altered vision of colonised Australia. And as much as the archive in the National Library of Australia will inform and elucidate there are other sources, other memories, that bring his legacy into the present and perhaps make it answerable to the challenges of today. Perhaps it is possible to turn the lens on the anthropologist and contemplate the slow but still dynamic ripples of his impact on the world. How to survey the surveyor?

In most histories of anthropology there is a missing category: the human subjects who became anthropological objects. This is why the Mathews legacy is fascinating. For all the attempts of the Spencers and Frazers to scrub a maligned amateur from the footnotes of anthropology, his influence has been felt in ways that are distinctly localised, though their repercussions are much wider.

Let's travel to the South Coast of New South Wales. The year is 1965. A rendezvous occurs between a man and a woman, each with their instrument: hers is a tape recorder; his, a leaf. Stan Mundy, an Aboriginal man of the New South Wales South Coast, played a tune on the gum leaf. He explained that the tune accompanied a song called 'Jacky Jacky is a Smart Young Fellow' and he sangs some of the words. These include a chorus in Aboriginal language, but as he explained to the interviewer, Janet Mathews, he did not understand the meaning. ${ }^{10}$

The themes opened by this encounter - or to be specific the after-image of an encounter - are immensely complex. Here in the living time of listening to the tape can could be heard a vanished time, the occasion of Stan Mundy's performance, the mood of which is irrevocably influenced by the awareness, even then, that the sound he was producing perhaps wavered on the edge of disappearance. The real time of the 'hear' and now, the imagined time we reconstruct by engaging with the tape, the lost time of the vanished sound. Certainly, the mood of the recording and the sentiments it might induce are influenced by the plaintive, indeed haunting, notes of the eucalyptus leaf - 
plucked from 'our' national tree. The particular poignancy of the gum leaf is due in part to its geographical specificity. It is a sound indigenous to this portion of the earth.

While Stan Mundy remembered the tune, he recollected only part of the lyrics. The fragments he recites indicate that this is a parody, sung by Aborigines: a song about that old caricature of themselves, Jacky Jacky - an appropriation. Significantly, the song had a chorus, apparently in an Aboriginal language, of which Mundy knew the words but not the meaning. He was not alone in this predicament. But fortunately the song in its entirety has not been lost. It was Jimmy Little Senior of Wallaga Lake on the New South Wales South Coast and father of the Jimmy Little, still singing today, who recorded it for Janet Mathews in 1965.

Jacky Jacky was a smart young fellow

Full of fun and energy.

He was thinkin' of gettin' married

But the lubra run away you see.

Cricketah boobelah will-de-mah

Billa na ja jingeree wah.

Jacky used to chase the emu

With his spears and his waddy too.

He's the only man that can tell you

What the emu told a kangaroo.

Cricketah boobelah will-de-mah

Billa na ja jingeree wah.

Hunting food was Jacky's business

Til the white man come along.

Put his fences across the country

Now the hunting days are gone.

Cricketah boobelah will-de-mah

Billa na ja jingeree wah.

White fella he now pay all taxes

Keep Jacky Jacky in clothes and food.

He don't care what become of the country

White fella tucker him very good.

Cricketah boobelah will-de-mah

Billa na ja jingeree wah. 


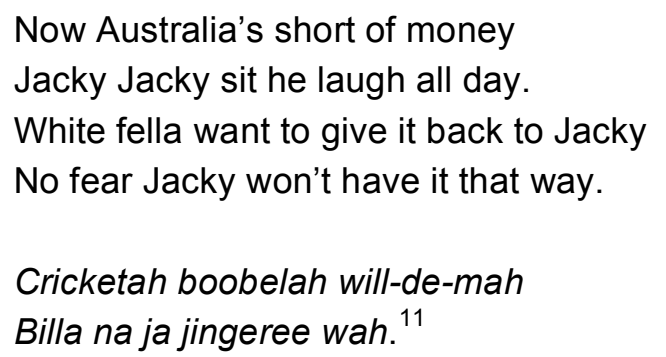

Beneath the outrageous humour and wonderful expression of political incorrectness, a tone of mournfulness underlies this remarkable song which is an example of the post-contact musical traditions never recorded by R. H. Mathews or other anthropologists, although they certainly existed. The reality is that an anthropological object could never be presented as an historical subject. Under the science-based rubric of the time, they were the productions of nature rather than culture.

Like Stan Mundy, Jimmy Little could recall but not comprehend the words of the chorus. Like any refrain, they offer a continuity, a centeredness, in the performance event of the song. But what an unstable centre it actually is. The meaning is opaque to the singer, and presumably his audience, though its historical nuances seem clear. Among the many things that have disappeared with the colonisation of this continent, the loss of language is cause for a particular experience of grief. The situation where languages are dying, where old people have no one left with whom they can converse, is paradigmatic to the historical experience of Aboriginal people across many areas of Australia. The 'Jacky Jacky' song seems born of this reality, a tragedy that affects not only those last speakers of the dying languages but the people around them, the folk who have heard their native tongue but do not know it, or who speak it only through surviving place names and isolated words or expressions.

In 2000 I interviewed Roy Barker of Lightning Ridge whose father, Jimmie Barker, was Janet Mathews' most remarkable talent. He recorded autonomously, then posted his work to Janet for lodgement in the archive of the Aboriginal Institute in Canberra. Barker compiled 110 tapes - and still more in interview with Janet - containing life story, mythology, philosophical musings, social history and documentation of Muruwari, a language of which he was among the last speakers. In my radio documentary This is Jimmie Barker Roy Barker described being 'devastated' when he first heard the tapes. It was a kind of post mortem experience of encountering the language he had never been taught. Despite the pain they provoked, Roy ended up acquiring cassette copies of his father's achive which he uses to pick up elements of Muruwari vocabulary and grammar. ${ }^{12}$ The anthropological record, however problematic its politics of appropriation, provides a resource to Aboriginal communities today - an example of what the archaeologist, Denis Byrne, calls 'archaeology in reverse. ${ }^{13}$

From the 1960s through to the 1970s, Janet Mathews worked with the 
Dharawal and Thurga people of the NSW South Coast, then in other parts of NSW, recording songs, language and stories. Her employer was the newly formed Australian Institute of Aboriginal Studies, to which Torres Strait Islanders were later added (AIATSIS). A well-to-do woman of upper middle-class background, she had no qualification as an ethnographer or ethnomusicologist, though she was an accomplished pianist, a music teacher, and a friend of the parliamentarian W. C. Wentworth who advanced her name when, against the odds, he managed to convince the Menzies government that the formation of an institute that would collect and store the remaining fragments of Aboriginal culture was not only a fitting way to spend taxpayers' money but a duty to the nation and indeed the world. ${ }^{14}$

An institution such AIATSIS, especially in the early days when its governance was the preserve of white experts, was inextricably related to the sense of disease or melancholy that is peculiar to the intimation of loss and disappearance a sensation endemic to many Aboriginal communities, although arguably it is felt, to varying degrees, across all cultures. To some extent AIATSIS was predicated on the technological opportunities opened by portable tape recorders which became available post-World War II. Part of my interest here is to study the relationship between the anxieties produced by a sense of impending disappearance and the processes of documentation, which, though always unsatisfactory, might just possibly curb its ultimate finality. To consider this relationship as it unfolds over time can provide unique understandings of modernity which, from this perspective, assumes a curious duality since it has been both rapacious in the levelling of traditional minority cultures, while simultaneously providing the technology and methodological apparatus for their imperfect preservation.

The 'Jacky Jacky' song provides just a single avenue on the influence of R. $\mathrm{H}$. Mathews whose attempts at cultural salvage and preservation arguably laid a foundation for the work of people like Janet. Her credibility on the South Coast and in other areas of New South Wales was considerably improved when word spread among the Aboriginal community that she was indeed connected with that other Mathews who had spoken to the parents or grandparents of people she encountered in the 1960s. It is a curious story for Janet Mathews, who was born in 1914 and died in the early hours of 1992, never met the anthropologistsurveyor. She was a Mathews by marriage only, the wife of R. H.'s grandson, Frank Mathews. So their relationship, you might say, was based on kinship, a subject on which R. H. wrote scores of papers. (Like other ethnologists of the period, he was heavily preoccupied with the marriage customs of Australian Aborigines.) So his influence on Janet was not directly personal and it was not in the blood. But his reputation fuelled her own investigations and were it not for the family connection it is unlikely that she would have thought to take such an initiative as sending Jimmie Barker a copy of R. H.'s paper on the language of the Muruwari which Barker, on tape, reads through, discusses and corrects. ${ }^{15}$ Here is a scenario that R. H. Mathews could barely have imagined. Like so many people 
of his day he was convinced that the Aboriginal race - his term, not mine hovered at the edge of disappearance. However erroneous this assumption, it certainly fuelled the urgency of his investigations.

If $\mathrm{R}$. H. influenced Janet, she in turn has influenced the impressions one gets of him now. It is thanks to Janet that the R. H. Mathews papers were mostly separated from those of the long-serving professor of anthropology, A. P. Elkin, who had them 'on loan' from the family for no less than twenty-five years and who published, in a three part article in the journal Oceania, what is to date the most complete account of the older Mathews' practice - an attempt to salvage his reputation from the mauling it had suffered from Elkin's own anthropological rivals such as A. R. Radcliffe-Brown. ${ }^{16}$ Janet also recorded insights on her grandfatherin-law that were gleaned from both family memories and her experiences in the field. At the instigation of the archaeologist, Isabel McBryde, who was then researching R. H. Mathews' entry for the Australian Dictionary of Biography, Janet recorded an oral history with her husband, Frank Mathews, in 1971. Here is an extract tape from that encounter:

FRANK MATHEWS: I was only young of course when he died. I know he was a stickler for proper conduct and that people should behave in the way that he and all his family, his brothers and sisters, had been brought up to behave, and he was quite strict... and had a strong sense of moral right and wrong... Otherwise he was a strong character of course, there's no doubt of that, and quite a strong personality. Apart from that I'm afraid I can't give you very much because I was only fifteen when he died.

JANET MATHEWS: Yes. I do remember one little story in particular that Uncle Bill said - how he was... taken so often to La Perouse with his father and his father would tell them to go and play on the beach or amuse themselves and he'd disappear into one of the little humpies and the children would play around, sometimes for so long they'd get rather tired of it and Uncle Bill at one stage thought, oh, he wished the old man would hurry up and go home so he popped along and looked inside and saw old Mrs Timbery who was one of his best Dharawal informants sitting on a box, [and] your grandfather was sitting on a box with his notebook and his pencil, writing very hard. They were both smoking pipes and Uncle Bill was waved away and they just had to go and wait...

I think l'd like to add a little bit of the impressions that l've had from the Aborigines that remember him - which was rather a surprise to me because when I first started doing fieldwork on the South Coast oh I just felt he was Grandfather-in-Law, and had written books and it really was magnificent what he'd 
done, but he didn't seem to be a real person to me until - I was very new at the game - I was at Wreck Bay at the reserve... It was my first visit there, and I knocked on the door of a $\mathrm{Mr}$ Howard Timbery and his wife... I'd said that my name was Mathews and I was just at the gate and going when he said, 'Would you be any relation to the old man who used to come to La Perouse?' which amazed me and I said: 'Yes, he was my grandfather-in-law.' And to an extent from that time on work on the South Coast became very much easier for me because there had been a lot of antagonism for various reasons... ${ }^{17}$

The Mathews tape is one of the most surprising discoveries in this human survey, putting a good deal of living flesh on those biographical bones. It provides access to material that wasn't included in the public archive including readings from a document that the National Library of Australia has just recently acquired from Mathews' descendants - a biographical sketch, based on discussions with Mathews as an old man, which were then written up by one of his sons, William the 'Uncle Bill' referred to on the tape. There is vital data about his education and early years.

We learn how Mathews, the son of Northern Irish protestants, was born at Narellan southwest of Sydney in 1841. Later his family moved to a farm at Breadalbane near Goulburn on the Great Southern Road and it was through this proximity to the highway that Robert had certain formative experiences. Somewhere around 1855 the young boy met a surveyor called John F. Mann. Intrigued at his activities, Robert devised his own games in imitation. He tells how he made a surveyor's chain from bark and played at measuring the country with an Aboriginal boy.

As a young man $\mathrm{R}$. $\mathrm{H}$. Mathews was involved in various rural activities including droving stock to Queensland. But his old interest in surveying never diminished and he undertook formal training in the profession, passing his final exams in 1870. Then followed the hard years as a district surveyor, stationed in central and western New South Wales. He married Mary Bartlett of Tamworth in 1872 and began a family. They had six children in total, one of whom, Australie, died quite young. The Mathews settled in Singleton in 1880, a period of evident prosperity. In 1882-83 Robert and Mary travelled the world, leaving their children with a nanny. Mathews never really worked full-time as a surveyor after returning to Australia. Other interests began to dominate. In 1883 he became a Justice of the Peace for NSW. He was also a district coroner and was sufficiently versed in legal practice to publish Handbook to Magisterial Inquiries in New South Wales in 1888. This was his first foray as an author. Mathews was also involved in various business dealings around Sydney, one of which - a failed mining venture seems to have cost him a large amount of money. Because his sons were enrolled at the King's School in Parramatta - then on the western edge of Sydney - the family moved once more in 1889 to a house near the school called 
Carcuron. R. H. Mathews would live there until his death.

The familiar pattern of Mathews' life was broken in 1892 when a minor surveying job came up. He was to measure blocks for one Benjamin Richards who had property at Bulga in the parish of Milbrodale near Singleton. Mathews and his son Hamilton were going about the survey when someone on the farm told them about an Aboriginal painting showing a human figure in a cave. This remarkable art site in the territory of the Wonnaruha people can still be visited today and as the local policeman told me when I went to look at it some years ago (long before I ever knew there was a Mathews connection), it goes by the name of the 'Milbrodale Man'. Mathews sketched and described this impressive figure, supposedly a representation of Baiame, the creation-hero of southeast Australia, who is sometimes known as 'the big fellow in the sky'. In subsequent years, Mathews would do much to plot the movements made by Baiame during his time on Earth. But he evidently did not anticipate how the course of his life would be altered when he surveyed the site, sketched the painting with the aid of his instruments and composed a description of the rock art which he presented to his colleagues at the Royal Society of New South Wales, the scientific association to which he had belonged since 1875 .

The published article describes the painting and site which, he speculates, was the location for ceremonial activities. 'I have confined myself,' he wrote, 'as much as possible to descriptions only of these drawings, and have not attempted to connect them with the myths and superstitions of the Australian aborigines... I have left these researches for those better qualified to follow them than I am, or have more time at their disposal. ${ }^{18}$ Of course he would have hoped, though he did not know, that his documentation of rock art, which became an almost frenzied passion over the next year, would win him the Society's medal and a prize of $£ 25$ - probably the only remuneration he ever received for the years of work that followed. What was it about the figure of Baiame with his arms outstretched? Christ-like you could say. For the change in Mathews was as startling as any religious conversion. The alteration is palpable as I peruse those sketchy diaries, one line a day if that, which take us from the world of the parttime surveyor and magistrate to a regimen that was almost exclusively anthropological research. Trips up and down the coast to the camps and reserves at La Perouse, Hawkesbury River, Burragorang Valley, Tabulam, Brewarrina, Goodooga: anywhere Aborigines might be gathered.

The notes crammed onto the backs of old envelopes and scraps of paper, the exercise books filled with drafts, provide a certain rebuttal of something for which Mathews has been criticised: that he relied on correspondents rather than interviewing informants himself. The reality, it seems to me, is that Mathews used all means at his disposal in conducting his research. He was clearly trying to build up cultural patterns for the Australian continent. He could hardly hope to scour its length and breadth with his limited means. The gathering of correspondence from around the country, while deemed suspect in anthropological terms, could be regarded as one of the unique aspects of his archive. Ethnology at this time was 
deeply influenced by the 'do it yourself' traditions of natural history.

The letters amassed by $\mathrm{R}$. H. Mathews are at times like a vast opinion poll on matters to do with race, culture, colour: an emotional spectrum that ranges from empathy, intimacy, indications of prowess in Aboriginal languages, extending to the harshest cruelty. The letters are from people in locations that Mathews sometimes visited by train or Cobb \& Co or rented horse. Others wrote from places he would never visit. They are all sorts of people: policemen, graziers, missionaries, explorers, cranks. Some are now famous such as Daisy Bates and Carl Strehlow but most are obscure. Packed into folders, the letters fill boxes in the archive, a strange, fabulous and sometimes disturbing world, an extraordinary survey, you could call it, of the white man's attitude to the black.

I say man and I mean it. The women you can count on one hand. Yet when they appear in the archive, the impressions are indelible. 'Dear Mr Mathews,' wrote a Mrs Gourley from Mt Eva, South Australia in 1900:

Your letter has been on my mind but have been ill in bed and lost my little one, as it came too soon only had the black women and they were very good they press down the back a firm gentle pressure all the time bringing the hands gradually downwards. They tie the naval string... and bring it in a round ring fixed on the child which is kept naked like this [letter includes a diagram] a string going round the neck the one I looked at was done with rabbit fur made into string... We are very interested in the blacks but this tribe is very dull, dirty, on the whole and lazy, of course there are exceptions... I don't believe they have any traditions but will try and find out. ${ }^{19}$

As much as the letters express distance between the Aborigines, 'our black boys', who laboured on farms, they at times reveal a surprising degree of intimacy. A Queensland correspondent in 1898 expressed the view, repeated countless times, that the 'blacks in these parts are dying out very fast. They have taken to all the worst vices of whites and the result is a rapid decrease.' Yet amidst such claims is an astonishing amount of evidence that customs and ceremonies in the 1890 s and early 1900 s were actually surviving - at least to some degree - the experience of contact. An Alfred Walker of Innaminck Station, South Australia, wrote to Mathews in 1899, revealing that initiation practices of circumcision and sub-incision were still practised among his 'black boys' working on the property. Some, he writes, 'have the underneath pipe that runs along below the penis cut clean out within an inch of the testicals [sic]. I know that that is correct as those boys have all been attended to by myself with ointment $\& \mathrm{c}$. to get the wounds healed up quickly. ${ }^{20}$

That a white grazier should bring his medicine to the private parts of young initiates is as surprising an image of the relationship between coloniser and colonised as you would be likely to find. For all the literature on the subject, there 
is still so much to be done in understanding the complexities of empire. Of course much of what we read in these letters is more or less what you might expect. The sheer eccentricity of Mathews' hope that farmers in remote regions would assist him is eloquently expressed by D. McLean of Yantara in NSW, writing in 1905:

I certainly have not time to spare to sit in office with a blackfellow or gin to talk patiently with him or her... If you can send a few inches of rain I might then have time to go into the question of niggers' grammar but under present conditions am not interested.

Trusting you will find some correspondent with more than two hands and wishing you success. ${ }^{21}$

For amidst all the paperwork that reveals the seriousness of, if not the underlying motivation for, Mathews' project of subjecting the lives and traditions of Aboriginal Australians to what he considered scientific documentation, one can almost forget how bizarre this must have been for the majority of his contemporaries. I find an undated press clipping pushed into an envelope among the Mathews papers. It seems to encapsulate the climate:

At the Electra Street Mechanic's Institute, Williamstown, last night, Professor Baldwin Spencer gave a lecture on 'The Northern Territory and its Aborigines.' Professor Spencer made pointed allusion to the undesirable menace offered by the near presence of the millions of inhabitants of Java, China and Japan. He also showed the 'position of isolation which the few white women in the Territory occupied, often residing on a station 100 or 200 miles distant from the next. Glimpses of the fine scenery existent in the river country with some beautiful cascades, were given by means of moving pictures and the camp life of the blacks was also depicted. Not the least interesting portion of Prof. Spencer's entertainment was the phonograph records of the songs and cries of the aborigines, which caused much laughter. ${ }^{22}$

For underlying this turn-of-the century period, in many ways so impressive for its democratic ideals, votes for women and welfare reforms, was an utter suspension of compassion when it came to people of colour. '[A]ll that can be done is to gather the few remnants of the tribe into some mission station where the path to final extinction may be made as pleasant as possible,' wrote Gillen and Spencer in The Native Tribes of Central Australia. ${ }^{23}$ No one, including the small band of anthropologists, found it surprising that the constitution for the emerging nation excluded Aborigines from the census. The blackfellow played no part in conceptions of the body politic; no role in the vision of a collective self. Jacky 
Jacky was just a joke.

The Two Worlds of Jimmie Barker is the autobiographical narrative that Janet Mathews drafted from Jimmie Barker's tapes. He tells of his family's removal from the pastoral station Milroy where his mother was a maid. They were sent to the mission station at Brewarrina in northwest New South Wales where, instead of waiting to become extinct, Barker, like thousands of others, married and had a large family. The book contains a moving remark about the difficulties he faced, when, against the odds, he learned to read:

At Milroy I had been quite unaware of any discrimination; there may have been some but I did not notice it. Now that I was able to read I found that the Bulletin and newspapers were full of derogatory stories about blacks and 'Jacky Jacky'. Some were in the form of jokes, but the joke was always on Jacky, who never knew as much as the other fellows. ${ }^{24}$

The carapace left by Robert Hamilton Mathews poses very real problems. They are exemplified as I look through the dozens of Aboriginal portraits and photographs that Charles Kerry, a contemporary of Mathews, sold as post-cards. Hundreds of his images are held in the National Library of Australia collection. These are the sorts of camps that Mathews visited when documenting the customs, habits, rites and folklore; places which he approached (according to Elkin who was told this by Enright) not by marching straight in but, acting in accord with Aboriginal custom, he would sit outside the camp, light a fire, and wait to be invited into their midst. ${ }^{25}$

For all the extraordinary data he recorded, the absences in the anthropology of Mathews and his contemporaries are so prominent that at times they almost scream. As anthropological objects, the people studied were of no interest as historical subjects. I look at their portraits and think of the things they must have seen. No anthropologist of this era, so far as l'm aware, ever described a massacre or what it was like to lose access to one's ancestral country. Mathews was perhaps a little more lenient in this regard, for his principle was to plainly depict what he saw, and when a woman in a skirt or a man with an axe appeared on a rock engraving, he simply put it down in his notebook.

In a project like this there are places where you cannot go. Without permission of descendents, I would not show examples of the extraordinary scenes of an initiation at Quambone in northwest New South Wales, photographed by Kerry who was apparently inspired by Mathews' documentation of the same ritual. That album must, for the moment, remain closed. But reading through accounts of the numerous boras and other ceremonies that Mathews recorded in New South Wales, southern Queensland and Victoria - rituals, in many cases, that were then occurring for the last time - I am left to wonder at the attitudes of those men who admitted him to their inner circle, who explained the details as he wrote them down, and whether, in so supporting the surveyoranthropologist, they were anticipating the possibility that one day the archaeology 
might, to some extent, be reversed.

\section{Endnotes}

\footnotetext{
${ }^{1}$ Martin Thomas was a Harold White Fellow at the National Library of Australia in 2002 where he studies the papers of R.H. Mathews. This article is developed from his Harold White lecture given at the Library.

${ }^{2}$ R. H. Mathews, 'Ethnological Notes on the Aboriginal Tribes of New South Wales and Victoria', Journal and Proceedings of the Royal Society of New South Wales, vol. 38, 1904, pp203-04.

${ }^{3}$ Van Gennep to Mathews, 1 July 1907, R. H. Mathews Papers MS 8006/2/13, NLA, Canberra.

4 Van Gennep to Mathews, 16 November 1909, ibid.

${ }^{5}$ W. J. Enright, 'The Initiation Ceremonies of the Aborigines of Port Stephens, N. S. Wales', Journal and Proceedings of the Royal Society of New South Wales, vol 33, 1899, pp115-16.

${ }^{6}$ Spencer to Fison, 30 September 1901, Spencer Collection Box 1, Pitt Rivers Museum, Oxford.

${ }^{7}$ Andrew Lang, Social Origins, London, Longmans, Green, and Co.1903, p38.

8 Spencer to Frazer, 13 June 1903, Spencer Collection Box 5, Pitt Rivers Museum, Oxford.

${ }^{9}$ Frazer to Spencer, 19 April 1908, ibid.

10 Interview with Stan Mundy, AIATSIS Audio Archive A1020, Canberra.

11 Interview with Jimmy Little Sr, AIATSIS Audio Archive A1021, Canberra.

12 Martin Thomas, This is Jimmie Barker, broadcast on Radio Eye, Radio National, Australian Broadcasting Corporation, 25 March 2000.

13 Denis Byrne, 'Archaeology in Reverse', in N. Merriman and T. Schadla-Hall (eds), Public Archaeology, New York and London, Routledge, 2000.

14 For information on Janet Mathews see Martin Thomas, "To You Mrs Mathews": The Cross-Cultural

Recording of Janet Mathews 1914-1992', The Australasian Sound Archive, vol 29, 2003.

${ }^{15}$ Recording by Jimmie Barker, AIATSIS Audio Archive A1706, Canberra.

${ }^{16}$ A. P. Elkin, 'R. H. Mathews: His Contribution to Aboriginal Studies: Parts I-III', Oceania, vol 46, 1975.

17 Interview with Frank Mathews, AIATSIS Audio Archive A1954, Canberra.

${ }^{18}$ R. H. Mathews, 'Rock Paintings by the Aborigines in Caves on Bulgar Creek, near Singleton', Journal and Proceedings of the Royal Society of New South Wales, vol 27, 1893.

19 Gourlay to Mathews, 9 July 1900, R. H. Mathews Papers MS 8006/2/1, NLA, Canberra.

20 Walker to Mathews, 6 January 1899, ibid.

21 McLean to Mathews, 8 December 1905, ibid. MS 8006/2/7.

22 'At the Electra Street Mechanics' Institute...', undated, ibid: MS 8006/2/13.

${ }^{23}$ W. Baldwin Spencer and F. J. Gillen, The Native Tribes of Central Australia, New York, Dover, 1968, p18.

24 Jimmie Barker and Janet Mathews, The Two Worlds of Jimmie Barker: The Life of an Australian

Aboriginal 1900-1972 as told to Janet Mathews, Canberra, Australian Institute of Aboriginal Studies, 1980.

${ }^{25}$ A. P. Elkin, 'R. H. Mathews: His Contribution to Aboriginal Studies: Part Il', Oceania, vol 46, 1975, p132.
} 